- persistência de deficiências no ensino fundamental e no ensino médio, pro blema estrutural;

- proposta de cursos seqüenciais, previstos no art. 44, I, da Lei no 9.394 de 20.12.1996 (Lei de Diretrizes e Bases da Educação Nacional);

- proposta de programas de educação à distância, previstos nos arts. 80 e 47, § 3으, da Lei no 9.394 de 20.12.1996 (Lei de Diretrizes e Bases da Educação Nacional): possibilidade de cursos, tanto de graduação como de pós-graduação, nas modalidades semi-presencial, à distância e mesmo on line (ver proposta de Curso de Mestrado da Escola Nacional da Magistratura - ENM, órgão vinculado à Associação dos Magistrados Brasileiros - AMB);

- proposta de mestrados profissionais ou profissionalizantes, regulamentada pela Portaria $\mathrm{n} \times 80$ de 16.12 .1998 do MEC
- proposta de cursos presenciais de especialização, regulamentada pela Resolução n 3 de 05.10.1999 da Câmara de Educação Superior do Conselho Nacional de Educação;

- proposta de aproveitamento dos alunos dos cursos de pós-graduação stricto sensu como professores nos cursos de graduação;

- proposta do Plano Nacional de Educação no sentido de aumentar, em dez anos, a taxa de matrícula no ensino superior, na faixa de idade de 18 a 24 anos, dos atuais em torno de $12 \%$ para $30 \%$.

2. importância da Portaria no 1.886 de 30.12.1994 do MEC, cuja legalidade é hoje questionada em face da superveniência da Lei n 9.394 de 20.12.1996 (Lei de Diretrizes e Bases da Educação Nacional), ou de diploma análogo, como instrumento para alcançar-se uma maior qualificação dos cursos jurídicos.

\section{A Controvérsia sobre os Direitos Humanos}

\author{
Exnst Orugendhat
}

Professor Emérito da Universidade Livre de Berlin

\section{Conferência}

G que são os direitos humanos? Pode se dizer que existem universalmente? Qual o seu significado e o seu conteúdo?

Em primeiro lugar abordaremos qual Hoje faz cinqüenta anos que a Assembléí Geral das Nações Unidas proclamou a Declarafão Universal de Direitos Humanos.

Utma característica desta Declaracão é que alêm dos direitos liberais incluiu igualmente os direitos sócio-económicos.

Eu quero demonstrar porque isto foi correto.

TEXTO DA CONFERENCIA PROFERIDA NO SAL ÃO NOBRE DA FACULDADE DE DIREITO DA UIFRS POR OCASIÁO DO CONGRESSO INTERNACIONAL DE DIREITOS HUMANOS REALIZADO EM COMEMORACAO DOS CEM ANOS DA FACULDADE E DO CINOÜENTENARIO DA DECLARAÇÃO DA ONU. (tradução do Prof. Sérgio Borja ). Porto Alegre, 10 de dezembro de 1998. 9 h a significação de afirmar que existem.

Algumas vezes se fala dos direitos humanos como se fossem direitos naturais; alguns afirmam que nascemos com eles. Mas isto é uma metáfora pois um direito só pode existir se for outorgado. De um lado podese dizer que num Estado os direitos humanos não existem se não estão outorgados pela lei, se não estão contidos na constituição. Por outro lado, se se afirma que são naturais, quer isto significar que estes direitos são anteriores à lei, mas também, nesse caso, têm que ser entendidos como outorgados. Outorgados, nesse caso, por nossa crença moral. Através deste sentido é que se embasaria a sua existência universal. Dizer que dependem da constituição do Estado poderia levar a pensar num relativismo e que os direitos humanos per- 
tençam a uma cultura política particular. $O$ que é uma inverdade na razão direta de que os direitos humanos são uma componente necessária de legitimidade de um Estado moderno.

Que significa legitimidade? Sempre que os homens exercem um poder político sobre outros homens a questão fundamental é saber se os súditos submetem-se a este poder pela força ou, porque consideram este poder como legítimo e logicamente justificado. Esta justificação sempre tem uma base moral. A moral tradicionalista teve fontes transcendentais pois considerou sempre que o poder dos reis foi outorgado por Deus e que se transferia por descendência. A única fonte moral que permanece, quando uma moral tradicional é rejeitada, consiste naquela que se justifica através do interesse dos indivíduos, e como não se pode demons. trar que alguns indivíduos são mais valiosos que outros, em razão dos iguais interesse de todos, o poder do estado moderno só pode ser legítimo se se embasa de certa maneira sobre os interesses de todos e assim, nesta razão, a existência dos direitos humanos, teria que incluir-se como conteúdo desta "certa maneira".

Se encaramos a história dos direitos humanos na Europa e América constatamos que houveram vários acontecimentos e aspectos acidentais e se isto fosse tudo, eles representariam uma idiossincrasia destas histórias e culturas. A outra possibilidade, que eu quero defender, é a que contempla o desenvolvimento dos direitos humanos como um componente necessário daquela legitimidade que surge quando a legitimidade tradicional desaparece. Isso não quer significar que não houveram fato-

res acidentais dentro desta história. Quando falamos "acidentais" queremos dizer "acidentais" ao conceito de legitimidade como tal, pois precisamente isso nos permitirá, mais adiante, identificar certas inconsistências na concepção burguesa de direitos humanos e assim levar-nos a uma concepção dos direitos humanos mais ampla que se pode reivindicar como digna de uma concepção universal e necessária.

A fim de possibilitar nossa orientação na história dos direitos humanos nos parece importante distinguir duas fases:

Primeira - a fase antiga da história inglesa. Nessa fase o conceito de legitimidade era ainda tradicionalista pois se aceitava o direito dos reis governarem embora já houvessem concedido alguns direitos que significavam limites e garantias contra suas arbitrariedades (v.g. a existência no século XIII de não ser detido arbitrariamente). Ora, por outro lado, este tipo de concepção sobre a história dos direitos humanos poderia levar à opinião equivocada de que os direitos humanos seriam, em realidade, simplesmente espaços de liberdade dentro de uma ordem política, que por sua vez, fosse autoritária e não democrática.

O passo decisivo para que a democracia possa ser alcançada é aquele em que há uma alteração na legitimidade que modifica sua concepção de uma base tradicional para, evoluindo, fundamentar-se sobre a vontade do povo. $O$ poder político já não é mais algo contraposto ao povo. As fases em que gradativamente o sufrágio foi estendido ao povo inteiro não nos concerne aqui analisar, nem tampouco o problema das deficiências internas de uma democracia representativa. $\mathrm{O}$ que é importante é que poderia parecer que uma vez que o poder é transferido ao povo dar-se-ia, com este acontecimento, a legitimação do poder político e que os indivíduos, nessa situação, não mais necessitariam de espaços próprios contra este poder. $O$ representante clássico de uma tal concepção, de uma democracia sem liberalismo, foi ROUSSEAU. Segundo ROUSSEAU, o indivíduo transfere toda sua liberdade à vontade geral.

O problema com o qual nos vemos confrontados aqui pertence ao conceito de democracia. A democracia parece ser uma autonomia coletiva, mas quando se fala assim esquece-se facilmente que, conforme esta ótica, os indivíduos perderiam suà liberdade individual. Falar da autonomia ou liberdade duma coletividade implica uma certa ambigüidade muito perigosa. Assim, aceitando-se a ótica de ROUSSEAU, os indivíduos se converteriam praticamente em partes do estado mas sem vida própria como indivíduos. O problema foi analisado claramente nos debates travados na convenção constitucional dos Estados Unidos. $O$ que acabamos de caracterizar como o perigo da democracia lá o designaram como a tirania da maioria. Se a maioria tivesse o direito de decidir o que quer, poderia, por exemplo, aniquilar a minoria. Uma vez mais os detalhes de preocupação dos pais da constituição americana não importam aqui. Naquele tempo isto foi visto como um problema social. Os pais da constituição americana foram os representantes dos ricos; a maioria, que eles receavam, eram os pobres. Além disso o problema central considerado naquela ocasião, não foram os direitos individuais dos indivíduos como tal, senão o problema concernente à questão que diz respeito "a como se deve estruturar o governo". Os aspectos especiais não importam aqui e o que verdadeiramente importa, problema com o qual estiveram plenamente conscientes na ocasião, foi o que se refe. re ao princípio que propicia que se evite $o$ totalitarismo no âmbito da democracia. Podemos resumir o essencial da seguinte forma: se a ordem política quer ser legítima, a condição necessária, mas não suficiente, é que tem de ser democrática; o sistema democrático tem que conter garantias, por exemplo, para que a perda de uma votação não signifique a aniquilação do adversário; deve conter outras garantias contra os abusos a que está exposto o sistema democrático de votação indireta; independentemente disto, supondo-se o pleno funcionamento parlamentar na máxima perfeição permitida pela realidade, ainda assim, todos os membros do povo deveriam reter espaços que eles mesmos pudessem desenvolver como conseqüência de suas capacidades e atividades, sendo ainda, que estes espaços não poderiam ser infringidos pelas decisões políticas majoritárias. Estes espaços de liberdade individual constituem um contrapeso necessário dos interesses individuais, não ao poder tradicionalista autoritário, mas ao poder político como tal.

É importante sublinhar que esta concepção não é simplesmente uma opinião possível senão uma concepção necessária se a ordem política pretende ser legítima e se a legitimidade deve ser baseada sobre os interesses dos cidadãos. O que dissemos até aqui pode subsumir-se nos conceitos de liberalismo e democracia. Algumas vezes referem-se como se a outorga dos direitos 
humanos fosse uma parte integral da democracia, no entanto, entendemos a palavra democracia num sentido amplo, não simplesmente como " poder emanado do povo" senão como suplementação resultante dos direitos humanos. Este é o uso atual, mas não se deve esquecer que é complementado por dois fatores, quais sejam, o democrático no sentido estrito e o fator liberal.

Colocadas estas premissas, ainda assim estamos no início do problema, pois agora é que surge a primeira questão, seja, se o estado deve ser forte ou débil, isto quer dizer, quais são os seus deveres em relação aos direitos humanos. Somente deve respeitar os espaços de liberdade dos indivíduos ou também deve protegê-los e ainda fomentá-los? O segundo questionamento deflui da questão: se podemos considerar estes espaços somente como espaços de liberdade e se o termo "liberalismo" é o adequado para defini-los?

O representante clássico do liberalismo burguês foi JOHN LOCKE. Poderíamos considerá-lo como a figura oposta a ROUSSEAU pois para este o estado democrático tinha uma tendência totalitária, sendo que, para LOCKE, o estado tinha uma dimensão mínima que justificava sua legitimidade na medida em que garantia os direitos "à vida, à liberdade e à propriedade". Ora, esta fórmula não pode ser considerada como legítima, pois embora se respeite os interesses dos indivíduos, dos cidadãos, estes são somente os cidadãos de uma classe que tem propriedades e, a proteção da propriedade não teve somente o sentido de proteção contra as arbitrariedades do governo, senão também contra as possíveis incursões dos pobres, como segue sendo até hoje. Se tivéssemos que contemplar a LOCKE como a única alternativa a ROUSSEAU, cairíamos numa outra unilateralidade e isso poderia contribuir para consolidar a idéia de que os direitos humanos são a idiossincrasia de um sistema político particular.

Mas uma vez mais devemos distinguir entre os detalhes no conteúdo da concepção do liberalismo burguês e a idéia subjacente fundamental. A concepção liberal sujeita-se a possibilidade de dois tipos de crítica. Uma é aquela que se opõe a que os interesses dos indivíduos devam ser a fonte última de legitimidade. Esta crítica fundamental, como a encontramos em HEGEL, também em MARX e, da mesma forma, no comunitarismo contemporâneo, é uma crítica que é intrínseca a base da idéia de legitimidade. Esses críticos identificam o erro já no pressuposto axiomático de que, se somos indivíduos isolados já não somos seres sociais. Foram os próprios liberais que provocaram esta crítica pois através de sua hipótese originária, qual seja, que na hipó tese do estado de natureza os indivíduos estejam isolados inicialmente e só num segundo momento é que se daria a superação deste estágio pela celebração do contrato que criaria o estado. Entretanto o que é mais crítico, nesta concepção hipotética, é o que veremos mais adiante. $\mathrm{O}$ que importa aqui é que a referência aos indivíduos não significa uma negação do seu ser social, senão o significado de que só a eles, indivíduos, deve ser deixada a decisão de qual o grau devem conceberem-se e identificarem-se como sociais. Se os indivíduos e seus interesses não fossem a única fonte de legitimidade então, esta consistiria em entes supra individuais como o Estado de HEGEL e os costumes (Sitten) que ele evoca. A única coisa que o individualismo bem entendido exclui, é que se imponham ao indivíduo estruturas sociais como algo tradicionalmente ou divinamente já dado. $\mathrm{O}$ individualismo não propõe o egoísmo, embora não o exclua. A idéia é simplesmente de não partir de uma determinada concepção de vida, sendo que o fator social deve ser convertido em algo autônomo, como querem os indivíduos mesmos, sendo que a única coisa que se exclui é a possibilidade de prejudicar os outros indivíduos.

A outra crítica ao liberalismo, aquela que me parece legítima, não é aquela que ataca-o por seu individualismo, senão porque não toma em consideração os interesses de todos. Esta segunda crítica concentra-se na maneira com que o liberal descreve os espaços que se devem garantir ao indivíduo, ancorando assim sua razão nos interesses particulares de um determinado grupo social, desta forma inferir-se-ia que estaria assim passando por cima e ainda prejudicando os direitos de outros grupos. Esta crítica não se embasa, como a conservadora, numa coisa fora dos interesses e direitos dos indivíduos, senão se fica dentro desta esfera, observando simplesmente que a maneira liberalista de definir os direitos implica em prejudicar os direitos dos outros.

Pode-se explicitar a diferença entre estas duas críticas em relação ao egoísmo aquisitivo. Para a crítica conservadora do liberalismo a atitude de querer enriquecerse é condenável por si mesma, como forma de vida (e nisso também MARX foi conservador); para a outra crítica, essa maneira de viver é permissível e só tem que sofrer restrições quando for o caso de prejudicar os interesses dos outros.

Esta segunda crítica, que a mim parece ser a única legítima, conduz a uma revisão dos direitos como foram entendidos na tradição liberal, seja, como sendo os únicos direitos humanos. $O$ ponto de crítica mais óbvio é o que se refere ao direito irrestrito à propriedade desigual, combinado com à simultânea proteção estatal dessa propriedade contra os pobres. Mas a polêmica fundamental com a concepção liberal deve partir de um ponto de partida mais básico que é o conceito de liberdade. Enquanto este conceito permanecer sendo a base não discutida, o liberal pode sempre poder alegar que o pobre tem a mesma liberdade de adquirir a propriedade. Esta maneira de falar pressupõe o que se chama de conceito de liberdade negativa que define-se pela ausência de coação. Ninguém, diz o liberal, está impedindo o pobre de tornar-se rico pelos meios legais. A este argumento de liberdade negativa foi contraposto um outro conceito de liberdade que foi cognominado de liberdade positiva. Segundo este conceito, uma pessoa é livre não já se ninguém lhe impede, mas só se, primeiro, tenha capacidade e, segundo, se existam condições materiais para tanto. Este conceito de liberdade positiva representa um primeiro passo na crítica do liberalismo, mas como constataremos, não é ainda suficiente como matriz de liberdade positiva, suficiente para tomar em consideração os interesses de todos. 
Um aspecto curioso da literatura contemporânea, sobre os direitos liberais, é aquele que embasa o conceito de liberdade como aquele fundamental e incontestável para a legitimação política, curiosidade que advém do peso da tradição liberal. É certo que ser livre, possuir autonomia, poder fazer ou não o que nós mesmos queremos é de fato, um interesse fundamental dos homens, mas, isso não autoriza inferir-se como base de todos os interesses dos homens. Já o direito à sua vida ou, para exprimir isso de uma maneira mais geral, o direito à segurança física, que sempre foi um direito fundamental no liberalismo mesmo (em efeito foi o primeiro) não é um direito à uma ação, à uma liberdade. Uma pessoa só pode fazer uso de sua liberdade, de espaços de ação, se certas condições, quer dizer, certos interesses ainda mais fundamentais, são satisfeitos. O que está, por exemplo, morren do de fome, não pode fazer uso de nenhum direito de ação. $O$ fato da tradição libera ter vislumbrado o conceito de liberdade negativa como fundamental e suficiente para a caracterização dos direitos humanos tem sua razão em que essa tradição sempre pressupunha um grupo privilegiado para o qual aquelas condições prévias já estavam satisfeitas, com exceção da segurança física. As outras condições prévias são que a pessoa já tenha tanto a capacidade como também o acesso a recursos materiais que são necessários para o exercício daquela liberdade que é a condição para poder manter a sua vida. Crianças, idosos, doentes e incapacitados não têm a capacidade neces. sária. E aqueles que têm a capacidade mas não têm propriedade em geral não podem adquiri-la porque a propriedade já está re- partida. Os pobres estão em condição de ganhar a vida somente se aceitarem serviço dos proprietários e assim se fazerem dependentes de seu poder - nesse ponto devemos seguir dizendo o que já dizia MARX.

O sistema liberal dos direitos humanos é por conseguinte, se considerado como auto-suficiente, um sistema ilegítimo, porque, primeiro, não toma em consideração diferentes partes da população e, em segundo lugar, porque produz novas relações de poder em favor da classe privilegiada. $\mathrm{Ca}$ beria perguntar se não se poderia abrandar esta afirmação de tal maneira que esta concepção dos direitos humanos fosse pelo menos legítima para a classe privilegiada, mas uma tal relativização da legitimidade não tem sentido e, além disso, os liberais pressupõem seu sistema de direitos humanos como concebido no interesse de todos. Puderam afirmar isso porque fecharam os olhos para o fato de que aqueles que não têm recursos materiais não podem fazer uso da sua liberdade negativa e, segundo, porque foram inconscientes sobre a existência de outros grupos como crianças, mulheres, idosos e incapacitados, que foram sempre considerados como dependentes de varões adultos e capacitados, não sendo portanto, reconhecidos como sujeitos de direito, com o conseqüente reconhecimento de uma esfera concernente aos seus próprios direitos. Este fato que a tradição liberal não tenha explicitamente negado estes direitos, mas simplesmente tenha deixado de os levar em consideração, este fato permite, não só contrapor ao liberalismo uma concepção legítima de direitos humanos, mas, mais ainda, mostrar-lhe que o que é parcialmente legí- timo na sua concepção, conduz por si, por superação, a uma concepção mais ampla.

Isso tem conseqüências até para a base sobre a qual se deve colocar a questão da legitimidade sócio-política. Refiro-me à idéia de um estado natural hipotético e à idéia de um contrato hipotético nesse esta do natural, como base da sociedade e do estado. $\mathrm{O}$ que faz parecer esta base como inadmissível não é, como o foi para a crítica conservadora, o individualismo como tal, senão que esta base seria um ponto de partida somente para a classe privilegiada do liberalismo, quer dizer para os varões adultos e sadios que seriam iguais para a negociação do contrato; não sem razẫo, os filósofos clássicos que defendiam o estado de natureza, estabeleceram sempre o pressuposto duvidoso de que, naquele estado, todos fossem mais ou menos igualmente fortes (das mulheres naturalmente não se falava e muito menos dos incapacitados). Um sistema sócio-político de igualdade normativa nunca pode ser o resultado duma negociação entre pessoas desiguais. A idéia do contrato político negociado foi sempre o instrumento ideológico daqueles que acreditavam estar na condição de estabelecer um contrato mais ou menos simétrico.

Este ponto de partida podia parecer tão radical porque não somente colocava em questão a maneira como deveria ser o sistema político, mas também se o Estado deveria ser afirmado de forma generalizada. A questão posta desta forma referiu-se somente ao problema político e não ao social, resultando que as relações sociais de poder são mantidas e as políticas servem somente para reforçá-las. Partindo da perspectiva de interesses iguais de todos, deve- mos questionar como deve ser o sistema político somente quando se questiona de como deve ser, concomitantemente, o sistema social. Uma parte da população, como as crianças e os incapacitados não podem dispensar de ajuda; a idéia de um contrato é, para eles, impensável, e isso significa que na base da questão de sua legitimidade não pode conceber-se um estado de natureza senão quando se vislumbra a realidade que estamos imersos num estado de variadas dependências uns dos outros e a questão passa a ser a condição de como poderemos mudar estas dependências de tal maneira que podem ser consideradas como legítimas.

Em vez do conceito de liberdade da tradição liberal, para melhor conceber o problema apresentado, introduziu-se um conceito fundamental diferente. É neste ponto que o conceito de liberdade positiva apareceu, e a maior parte dos que reclamam direitos sócio-econômicos pode fazer uso deste conceito, embora ele não seja suficiente para visualizar a realidade das crianças, doentes e idosos. A estes não basta o estabelecimento de condições materiais para poder atuar senão uma ajuda direta para tanto. Eis aí, nesse instante, identificado o conceito fundamental que estamos buscando. Talvez se possa colocar dessa forma: para que possam prosperar ou florescer dentro do possível. Os espaços de direitos que um sistema político legítimo teria que outorgar a todo indivíduo não são somente espaços de liberdade, senão espaços que propiciassem o poder de prosperar e desenvolver-se.

Com isso não quero desprestigiar o conceito de liberdade positiva, nem 
tampouco o conceito de liberdade negativa, pois, com efeito, são centrais, não sendo no entanto suficientes. $O$ conceito de liberdade negativa, que os indivíduos devem ser livres de coação e violência, é sem dúvida fundamental para o conceito de direitos humanos. Também, da mesma forma, é correto que o próximo passo deve consistir na introdução do conceito de liberdade positiva. Ele é fundamental para a primeira ampliação dos direitos humanos além dos direitos e liberdades negativas, primeiro, porque a autonomia é uma necessidade fundamental humana e, segundo, porque só assim se pode aliviar a deficiência central do sistema capitalista que consiste em que muitas pessoas querem e poderiam ganhar a própria vida mas não podem. São impedidos de fazê-lo em face da constelação reinante no que se refere a propriedade e ao poder, em última análise, pela liberdade dos privilegiados.

Disto resulta, primeiro, o dever do sistema político, se quer ser legítimo, de criar condições de trabalho para todos que são capazes de trabalhar, resultando assim, o direito ao trabalho que é reconhecido em muitas declarações de direitos humanos mas não está realizado em nenhum país capitalista. Disto resulta também uma série de obrigações de criar condições de oportunidades iguais abolindo-se os colégios e universidades para as elites, abolindo-se, da mesma forma os direitos à herança. Ainda assim a idéia que faculta oportunidades iguais não poderá ser realizada em razão das vantagens que as crianças ricas já possuem por ser criadas em famílias com maiores facilidades, mas, de qualquer maneira, isto é um passo necessário. Enfatizar o conceito

de liberdade positiva é também importante porque sublinha o princípio de que ajudar deve significar, sempre que seja possível, ajudar e ajudar-se a si mesmo, e porque evita o mal entendido sistema social como se ele fosse um mero fornecimento de bens.

Não obstante, o princípio da liberdade positiva tem seus limites. Os que precisam, como as crianças da rua, os idosos, os incapacitados, não são somente condições materiais senão, da mesma forma, a possibilidade de sua capacidade de manterem-se. Eles têm que ser ajudados de maneira direta, ainda que também isso seja de uma maneira que sua autonomia seja fomentada o quanto for possível. Mas obviamente tais direitos, como a previdência médica e a assistência aos idosos não podem ser fundadas simplesmente sobre o conceito de liberdade positiva.

É certo que o reconhecimento dos direitos daqueles que não têm capacidade de trabalhar implica um peso moral adicional. Pois no caso anterior, onde se tratava somente de facilitar-se as condições de ganho de vida, aí, podia-se falar dum mero ato de compensação em face de uma injustiça. No entanto, como pode-se visualizar esta reclamação, para compensação de injustiças, no caso de uma repartição de terras? Neste caso pode-se dizer que a riqueza dever ser restringida porque ela mesma fora a causadora da pobreza. Nesse caso é mais fácil que o liberal de boa vontade reconheça a injustiça do sistema de direitos humanos reinante. Mas em relação àqueles cujas vidas e desenvolvimento não parecem ser prejudicados pelo sistema, os privilegiados, nesse caso, poderiam rejeitar toda respon- sabilidade, assim como também poderiam fazer face a uma responsabilidade similar ao danos produzidos por uma catástrofe natu ral. Mas a impressão que esta indigência seja independente do sistema econômico não tão convincente. Os ricos em geral não têm suas crianças nas ruas e eles podem proteger-se contra as doenças e as conseqüênci as da velhice ou das catástrofes naturais Talvez o liberal argumentasse que não contratara com esta gente marginal, e isso sig nificaria que ele poderia pensar, com efeito muitos pensam assim, que ele poderia considerá-los como estando fora do sistema e por conseguinte fora do rol de responsabilidades do próprio sistema. Com efeito, assim se pensa hoje em dia também em relação aos que têm capacidade de trabalhar mas sobram; o fato de ter mais gente que trabalho se diz que não é a conseqüência do sistema econômico, senão o incremento da natalidade e que isto não é uma injustiça, senão uma má sorte. Mas assim não se pode argumentar se tomamos uma posição não contratualista e se se concede que esta gente faz parte igualmente da sociedade que, por conseguinte seus interesses têm o mesmo valor; que cada um vale, pelo exposto, igual. Por isso seus direitos a serem ajudados têm que ser reconhecidos como direitos humanos. São direitos, e o sistema político, se quer ser considerado como legítimo, tem uma obrigação pois a ajuda não é considerada como um ato de graça.

Devo mencionar que a inclusão dos direitos sócio-econômicos no sistema dos direitos humanos não constitui somente uma extensão do conteúdo senão também uma mudança no sentido formal dos direitos humanos. Os direitos humanos foram considerados classicamente como dirigidos somente ao governo. Foi o governo que esteve obrigado a restringir seu poder. Mas hoje começamos a entender que o perigo para o indivíduo não é somente o poder do estado, senão o poder econômico dos outros indivíduos, e a obrigação do estado legítimo não consiste então em somente respeitar ele mesmo os espaços dos indivíduos senão em protegê-los, da mesma forma, contra o poder de outras pessoas e instituições. Esta obrigação de não somente respeitar senão proteger, parece entrar no pensamento jurídico contemporâneo através do que no direito alemão se chama Drittwirkung, ainda que ali se encontre caracteristicamente restringidos os direitos à liberdade clássicos. Assim, por exemplo, se reconhece que o direito à liberdade de imprensa é infringido inconstitucionalmente por um monopólio de imprensa.

A resistência contra a introdução dos direitos sócio-econômicos como verdadeiros direitos humanos se baseia, a parte do conceito restrito de liberdade, particularmente, sobre dois argumentos: primeiro que são vagos e segundo que custam dinheiro. Mas, como o autor norte-americano HENRY SHUE demonstrou em seu livro Basic Rights, editado em 1982, ambas as coisas podem se dizer igualmente própria aos direitos clássicos. Também o direito a não ser detido arbitrariamente o que em inglês se chama due process custa dinheiro ao estado e se pensamos no direito a segurança física, igualmente pode parecer arbitrário até que ponto o estado tem a obrigação de proteger e, por conseguinte, esse direito também é vago. 
Existe um terceiro argumento que demonstra a dificuldade da instituição dos direitos sócio-econômicos. Consiste na globalização da economia e da conseqüente maior dificuldade para o estado individual de submeter as regras da economia sob as leis estatais. Aqui, admito que surgem graves problemas, mas não se deve confundir a questão da dificuldade da instalação dos direitos humanos com a questão da sua própria legitimidade. A perspectiva da legitimidade exigiria a implantação destes direitos (ademais a globalização não deveria ser uma escusa fácil para não se fazer absolutamente nada).

Finalmente, devo mencionar que tanto o conceito de liberdade como o conceito de direito emprestam-se a abusos nos quais os dois conceitos perdem o sentido que têm quando se fala de direitos humanos. Por exemplo, na conhecida declaração do antigo presidente norte-americano ROOSEVELT, quando falou das quatro liberdades, entre elas da liberdade de indigência e da liberdade de medo, aí se alberga uma concepção bela travestida em palavras ilegítimas, porque quando se fala assim, duma liberdade $D E$ em vez duma liberdade A, por exemplo, da liberdade DE indigência, o ser livre é simplesmente um sinônimo da preposição "sem", e assim naturalmente pode-se combinar com qualquer coisa que se considera ser um desvalor Por exemplo, poderia-se falar da liberdade DE democracia e assim se poderia comprovar que a autocracia fosse um direito hu mano.

São sofismas que deveríamos evitar. Estes sofismas conduzem a uma diluição do conceito de direitos humanos e assim a um descrédito de todos os direitos humanos além dos clássicos do liberalismo. Hoje se fala na existência suposta de direitos humanos de terceira geração, em que as duas primeiras gerações, pela ordem cronológi$\mathrm{ca}$, seriam os direitos clássicos liberais e posteriormente os direitos sócio-econômicos. Não sei muito bem em que deve consistir esta terceira geração, mas dois exemplos são os direitos das coletividades, como o direito de uma minoria a ser autônoma e os direitos ecológicos. Se houvessem direitos de coletividades, isso não só seria uma nova geração de direitos humanos, senão um conceito totalmente novo porque os direitos humanos são essencialmente direitos de indivíduos. Creio que o direito à autonomia duma coletividade é em realidade redutível aos direitos dos indivíduos que constituem esta coletividade em poder autodeterminar-se coletivamente. Quanto aos supostos direitos ecológicos a primeira pergunta é: quem os têm? A natureza? Não acredito que tenha sentido falar da natureza como um sujeito que tenha direitos. Ou são os homens que teriam estes direitos, por exemplo, o direito ao ar e à água puros? Esta maneira de falar, uma vez mais se empresta a uma inflação de coisas às quais supostamente teríamos um direito, e isto também faria com que o conceito de direito humano perdesse o seu sentido. $O$ conceito de direitos humanos é esvaziado quando o utilizamos para qualquer coisa que se quer ter, como por exemplo silêncio ou estradas boas. No melhor dos casos a gente converte assim fatos que deveriam ser vistos sob a lei penal relacionados a supostos direitos humanos. A maneira correta de formular o que se quer dizer com o direito ao ar limpo é que aquelas pessoas ou instituições ou empresas, que são a causa de uma ocorrência prejudicial, deveriam ser castigados, como também deveriam ser, em ca- sos que não se referem a casos ecológicos. Em resumo, creio que é igualmente insus. tentável não se reconhecer direitos sócioeconômicos como também pensar que agora se poderia estender sua lista sem nenhum controle. 